\title{
Linear discriminate analysis and k-nearest neighbor based diagnostic analytic of harmonic source identification
}

\author{
Mohd Hatta Jopri' ${ }^{1}$, Abdul Rahim Abdullah², Mustafa Manap ${ }^{3}$, Mohd Badril Nor Shah ${ }^{4}$, \\ Tole Sutikno ${ }^{5}$, Jingwei Too ${ }^{6}$ \\ ${ }^{1,3,4}$ Faculty of Electrical \& Electronic Engineering Technology, Universiti Teknikal Malaysia Melaka, Malaysia \\ ${ }^{2,6}$ Faculty of Electrical Engineering, Universiti Teknikal Malaysia Melaka, Malaysia \\ ${ }^{5}$ Department of Electrical Engineering, Universitas Ahmad Dahlan, Indonesia \\ ${ }^{5}$ Embedded System and Power Electronics Research Group (ESPERG), Indonesia
}

\begin{tabular}{l} 
Article Info \\
\hline Article history: \\
Received May 9, 2020 \\
Revised Jun 25, 2020 \\
Accepted Jul 10, 2020 \\
\hline
\end{tabular}

Keywords:

Harmonic current source Harmonic voltage source K-nearest neighbor Linear discriminate analysis S-transform

\begin{abstract}
The diagnostic analytic of harmonic source is crucial research due to identify and diagnose the harmonic source in the power system. This paper presents a comparison of machine learning (ML) algorithm known as linear discriminate analysis (LDA) and k-nearest neighbor (KNN) in identifying and diagnosing the harmonic sources. Voltage and current features that estimated from time-frequency representation (TFR) of S-transform analysis are used as the input for ML. Several unique cases of harmonic source location are considered, whereas harmonic voltage $(\mathrm{Hv})$ and harmonic current $\left(\mathrm{H}_{\mathrm{C}}\right)$ source type-load are used in the diagnosing process. To identify the best ML, each ML algorithm is executed 10 times due to prevent any overfitting result and the performance criteria are measured consist of the accuracy, precision, geometric mean, specificity, sensitivity, and F-measure are calculated.
\end{abstract}

This is an open access article under the CC BY-SA license.

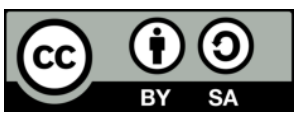

\section{Corresponding Author:}

Mohd Hatta Jopri,

Faculty of Electrical \& Electronic Engineering Technology,

Universiti Teknikal Malaysia Melaka,

Jalan Hang Tuah Jaya, 76100 Durian Tunggal, Melaka, Malaysia.

Email: hatta@utem.edu.my

\section{INTRODUCTION}

The increase in non-linear loads in the industrial, commercial and domestic power system has changed the utilities power quality conditions [1-3]. With the fast development in power electronics, the load behavior changes from linear to non-linear and these loads contribute harmonic pollution in electrical power system [4-6]. Harmonics caused complications such as operation failures of electrical equipment, power losses, overheating, and overloading of power system equipment [7-10]. Thus, it is vital to identify the most suitable methodologies to identify and diagnose the type of harmonic sources in the power system [11-13]. Various methods have been suggested by researchers due to diagnose the type of harmonic sources based on different theoretical principles, features, benefits, and drawbacks. Nevertheless, a high level of technical experience is required to properly diagnose the harmonic source type [14-16].

The literature on the diagnosis method using the stochastic approach and power quality indexing been explained in $[17,18]$. However, this method utilizes Fourier and wavelet transform signal processing techniques, whereas many constraints of these signal processing techniques are explained in [19-21]. Furthermore, a diagnosis study using a short-time fourier transform (STFT) and S-transform based on a rules-based classifier is introduced in [22-24]. However, high technical knowledge is essential due to 
distinguish the rules-based classifier threshold parameter values [25, 26]. Power quality analysis is a tricky task as the presence of complex-linear, as well as nonlinear patterns in the power quality event and old statistical method of auto-regressive integrated moving average (ARIMA), is introduced [27, 28]. To improve the accuracy of the ARIMA approach, the vector autoregressive model and artificial neural networks (ANN) are introduced [29]. This is due to capture the linear interdependence and uncover the non-linear aspects, whereas made this method difficult and complex to apply. Many researchers used statistical learning theory (SLT) for pattern recognition [30, 31]. In [32], Kumar used a neural network-based classification algorithm for distinguishing the disturbance signals. However, this method is not suitable to construct the frequency spectrum, thus results in the loss of frequency components that has low energy components [3]. A computerized optimization algorithm with the mechanics of natural genetics and natural selection option is known as genetic algorithm (GA) also been introduced in in diagnostic analytic [33]. The basic principal of GA is to calculate the highest survival probability of the fittest individual. The main advantage of this technique is, it use variables coding set as a substitute of actual variables. However, the drawback of GA such not applicable for dynamic data set, difficult to decide the fitness function, and the output accuracy is reliant on the problem knowledge [34].

The fuzzy logic (FL) and probabilistic neural network are used in [35] to distinguish type of harmonic sources. However, the total accuracy of this method is decrease whenever new type of load is introduced [23]. But, the FL has a drawback such as the design of the rule-based is complex, and FL is not flexible to new disturbance types [36,37]. The logistic regression is one the popular classification algorithms from the machine learning field [38]. The logistic regression is commonly used for classification compared to linear regression $[39,40]$. Nevertheless the logistic regression unable to solve the non-linear problems as its decision surface is linear and its great dependence on a proper data presentation [41]. This means that the logistic regression is not a advisable tool unless all the significant independent variables are obtainable [42, 43]. Until now, the artificial intelligence such as machine learning has become one of the vital techniques in the classification of the power quality system [44, 45].

Numerous works of literature were stated, that the common machine learning methods, for example, support vector machine (SVM), Naïve Bayes (NB), linear discriminate analysis (LDA), and K-nearest neighbor (KNN) offer satisfactory performance for classifying and diagnosis purpose [46-48]. This paper presents high accuracy, fast estimation, and costs effective technique to diagnose the type of harmonic sources in the distribution system with single-point measurement at the point of common coupling (PCC) by utilizing the machine learning algorithms [49,50]. The chosen machine learning algorithms are the LDA and KNN [51,52]. The LDA is one of the robust machine learning algorithms in this world. LDA not only simple but also efficient. Besides, LDA is faster and computationally less expensive. Generally, the main goal of LDA is to discriminate against the observed features by maximizing the posterior probability [53]. KNN is a common machine learning algorithm that has commonly applied in many engineering applications such as feature selection, pattern recognition, and fault identification [54, 55]. Among the modern algorithms, KNN can usually perform faster to achieve the results. The KNN not only simple but also computationally efficient [56]. In general, KNN predicts the class based on the $\mathrm{k}$ most similar training data using the Euclidean distance measurement [57]. At last, the best machine learning method for identifying and diagnosing harmonic sources is selected based on the performance measurement criteria such as the accuracy, precision, geometric mean, and F-measure [58-60].

\section{RESEARCH METHOD}

In this research two types of machine learning algorithms, namely LDA and KNN are employed to diagnose the type of harmonic sources. This is due to their excellent performance in the works of literature. The LDA has less computational complexity and able to discriminate the observed features by maximizing the posterior probability. In this work, LDA with linear function is implemented. Meanwhile, the K-fold cross-validation technique is utilized for performance evaluation. Initially, the data is allocated equally into $\mathrm{K}$ parts, and each part is used for testing in succession. Besides, the remaining parts are used to train the classifier. Instead of using a hold-out technique, the cross-validation technique is more preferred because it can prevent overfitting and bias results [47]. In this research, a KNN with $k=1$ is applied.

The main objective of this research is to classify and identify the location and type of harmonic sources that connected to the power system network The execution of the proposed method is realized using the single-point measurement technique at the PCC as presented in Figures 1 and 2 using IEEE 4-bus test feeders [61]. Furthermore, the measured voltage and current signals are analyzed using time-frequency analysis namely S-transform. The S-transform has been evolved which enjoys the advantages of both STFT and wavelet transform, while has a great advantage in detecting, and classifying the power quality. Two different types of harmonic sources consist of the harmonic current source $\left(\mathrm{H}_{\mathrm{C}}\right)$ and harmonic voltage 
source $\left(\mathrm{H}_{\mathrm{V}}\right)$ type-load are used in this research [62]. In addition, four explicit cases are considered in this research [63, 64]:

- N-N: no harmonic source in the power system (case 1),

- N-H: harmonic source located at the downstream of the PCC (case 2),

- H-H: harmonic source located at the downstream and upstream of the PCC (case 3), and

- H-N: harmonic source located at the upstream of the PCC (case 4).

Figure 3 presents an overview of the proposed method. To begin with the voltage and current signals are measured at the PCC. Next, the S-transform analysis is applied and then the signal parameters can be estimated from the TFR. Two types of feature sets are use as input to the machine learnings include current feature set, and voltage feature set. Finally, the location and type of harmonic sources are obtain using LDA and KNN. The best machine learning will be determined based on the performance measurement and explain in sub-section 2.2
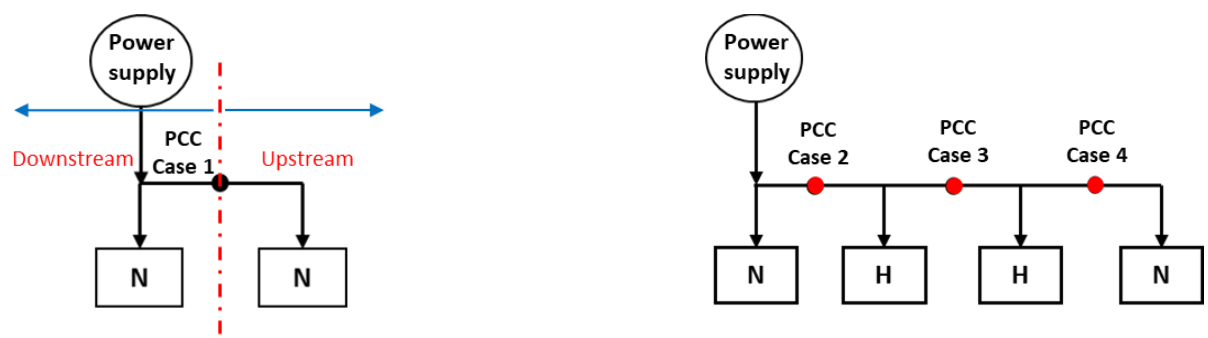

$\mathrm{N}$ is a non-harmonic source, which is resistor load, $\mathrm{H}$ is harmonic producing load $\left(\mathrm{H}\right.$ can be $\mathrm{H}_{\mathrm{C}}$ or $\left.\mathrm{H}_{\mathrm{V}}\right)$

Figure 1. Upstream-downstream for N-N

Figure 2. IEEE 4-bus test feeders for N-H, H-H, and H-N

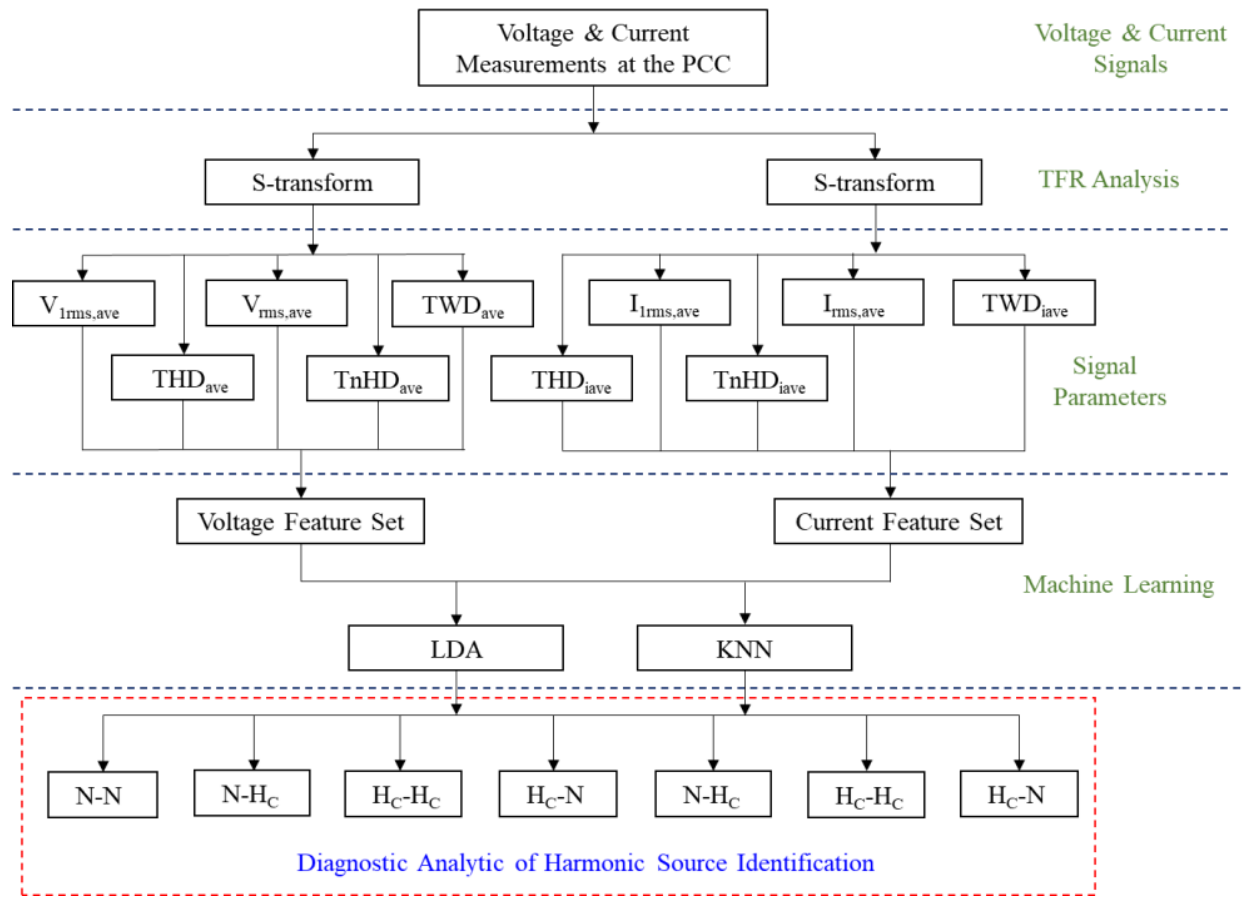

Figure 3. An overview of the proposed method

\subsection{Voltage and current feature sets}

The feature set consist of five signal parameters of each voltage and current signals $[65,66]$ :

- The average instantaneous RMS of voltage and current ( $V_{r m s, \text { ave }}$ and $\left.I_{r m s, a v e}\right)$

- The average instantaneous RMS fundamental of voltage and current ( $V_{\text {lrms,ave }}$ and $\left.I_{\text {lrms,ave }}\right)$

- The average instantaneous total harmonic distortion of voltage and current $\left(T H D_{\text {ave }}\right.$ and $\left.T H D_{\text {iave }}\right)$

- The average instantaneous total nonharmonic distortion of voltage and current (TnHD ave and $\left.T n H D_{\text {iave }}\right)$

- The average instantaneous total waveform distortion of voltage and current ( $T W D_{\text {ave }}$ and $T W D_{\text {iave }}$ ) 


\subsection{Machine learning performance measurement}

To prevent any numerical analysis problem, the estimated feature sets are normalized between 0 and 1. Subsequently, in the classification process, the feature set is fed into the KNN and LDA, which aims to diagnose the multiple harmonic sources. Note that LDA and KNN are running for 10 times, and the average results are recorded. For performance measurement, four famous evaluation metrics, namely accuracy, precision, geometric mean, and F-measure are used. The performance measurement techniques as follows:

\subsubsection{Accuracy}

The accuracy is a metric used to measure how accurate the proposed harmonic source diagnosis system can be. It is defined as [58],

$$
\text { Accuracy }=\frac{\text { No. of corrected diagnosed samples }}{\text { Total number of samples }}
$$

\subsubsection{Precision}

Precision is the proportion of the expected positive samples that corrected, and it can be expressed as,

$$
\text { Precision }=\frac{T P}{T P+F P}
$$

\subsubsection{Geometric mean}

Geometric mean (G-mean) is an enhanced version of sensitivity and specificity, and it can be calculated as [58],

$$
\text { Geometric mean }=\sqrt{\text { Sensitivity } \times \text { Specificity }}
$$

\subsubsection{Specificity}

Specificity is another commonly used metric in diagnosis, and it can be calculated as [58],

$$
\text { Specificity }=\frac{T N}{T N+F P}
$$

\subsubsection{Sensitivity}

Sensitivity is a commonly used metric in diagnosis, and it can be expressed as,

$$
F-\text { measure }=\frac{2 T P}{2 T P+F N+F P}
$$

\subsubsection{F-measure}

F-measure is an important metric that supports accuracy, and it is used to characterize the performance of a classifier. It can be defined as [58],

$$
F-\text { measure }=\frac{2 T P}{2 T P+F N+F P}
$$

Where TP is the true positive, TN is the true negative, FN is the false-negative, and FP is the false positive, which can be obtained from the confusion matrix.

\section{RESULTS AND DISCUSSION}

Table 1 tabulates the results of accuracy, precision, geometric mean, and F-measure for the identification of the harmonic sources using LDA and KNN for the voltage feature set. From Table 1, one can observe that the performance of LDA and KNN were deficient, which cannot identify the harmonic sources correctly. Even though LDA performed better than KNN, but LDA scored the accuracy of 38.69\%, which was lower than $50 \%$. This might be the weak discriminability of voltage features, thus leading to the worst performance in this work. Based on the results obtained, voltage features were not a proper choice for harmonic source identification. Table 2 displays the results of accuracy, precision, geometric mean, and F-measure for the identification of the harmonic sources using LDA and KNN for the current feature set. As can be seen, the performances of LDA and KNN were good. The result shows that current features were able to discriminate the classes between harmonic sources, which contribute to the optimal performance in this work. From Table 2, it is clear that LDA achieved better results as compared to KNN. This might be the high linearity of current features that gives the LDA to provide excellent performance while identifying the harmonic sources. 
Figure 4 and Figure 5 illustrate the confusion matrix of LDA and KNN for the identification of harmonic sources using voltage feature set. In these Figures, only N-N can be correctly identified (100\%). The performance of KNN was worst compared to LDA. Most classes of KNN were below 10\%, which made it fail to identify the harmonic sources correctly. Even though LDA was better than KNN, but its performance was still lower than $30 \%$ in most classes. In sum, voltage features are not suitable for harmonic source identification. Figure 6 and Figure 7 demonstrate the confusion matrix of LDA and KNN for the identification of harmonic sources using the current feature set. In these Figures, it shows that LDA and KNN were able to identify the harmonic sources very well, which offered high class-wise accuracy of above $90 \%$. With KNN, the Hc-N, N-N, and N-Hv were perfectly classified (100\%). However, the N-Hc, Hv-Hv, and Hv-N were lower than $95 \%$ class-wise accuracy. On the other hand, LDA scored $100 \%$ class-wise accuracy on Hc-N, N-Hv, and $99 \%$ on N-N. Only two classes, N-Hc and Hv-Hv were lower than 95\%, which was superior than KNN in harmonic sources identification. The result affirms the LDA can usually provide higher performance than KNN in harmonic sources identification.

Table 1. The performances of LDA and KNN using

\begin{tabular}{lcc}
\multicolumn{3}{c}{ the voltage feature set } \\
\cline { 1 - 2 } \multicolumn{1}{c}{ Evaluation metrics } & LDA & KNN \\
\hline Accuracy (\%) & 38.69 & 25.81 \\
Precision & 0.2987 & 0.1485 \\
Geometric mean & 0.4767 & 0.1760 \\
F-measure & 0.2948 & 0.1498 \\
\hline
\end{tabular}

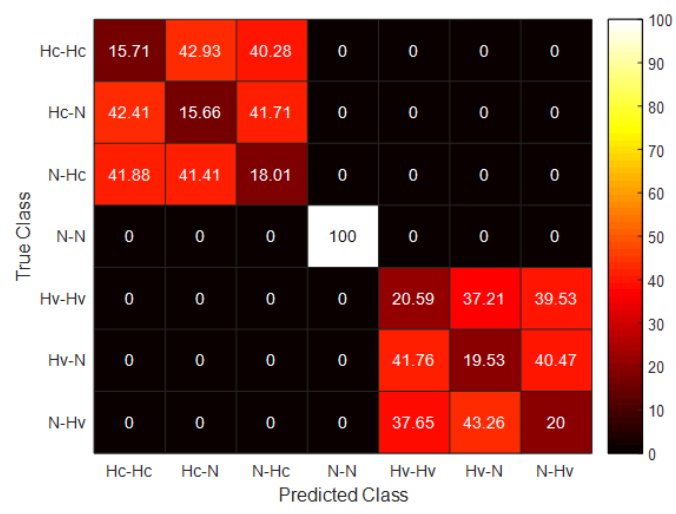

Figure 4. Confusion matrix of LDA using the voltage feature set

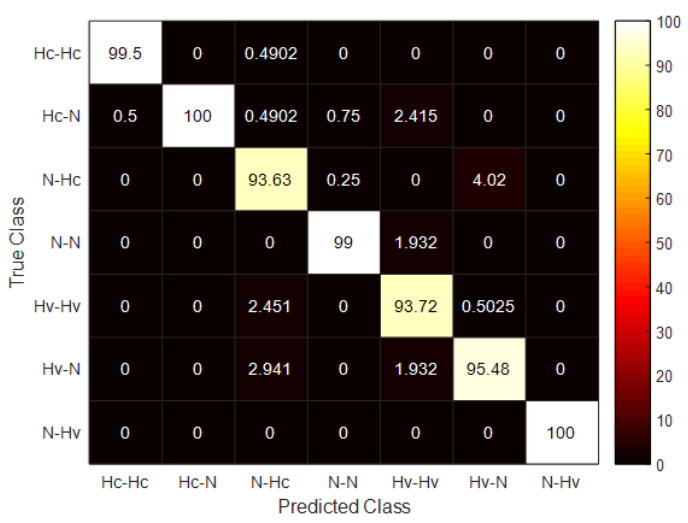

Figure 6. Confusion matrix of LDA using the current feature set
Table 2. The performances of LDA and KNN using

\begin{tabular}{lcc}
\multicolumn{3}{c}{ the current feature set } \\
\hline \multicolumn{1}{c}{ Evaluation metrics } & LDA & KNN \\
\hline Accuracy (\%) & 97.50 & 96.38 \\
Precision & 0.9733 & 0.9600 \\
Geometric mean & 0.9842 & 0.9761 \\
F-measure & 0.9730 & 0.9590 \\
\hline
\end{tabular}

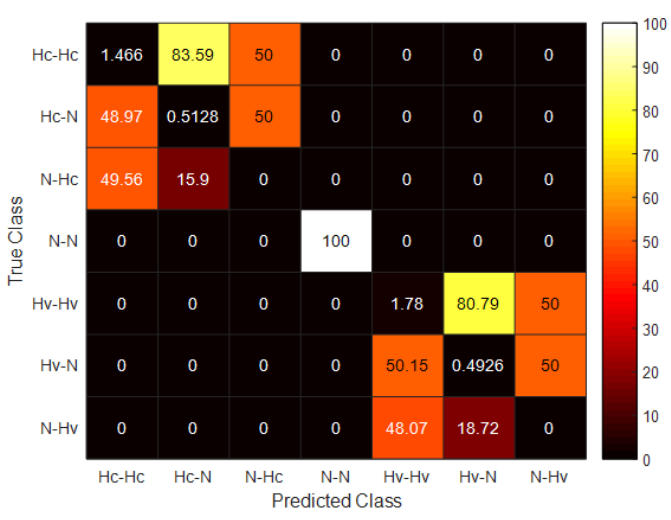

Figure 5. Confusion matrix of KNN using the voltage feature set

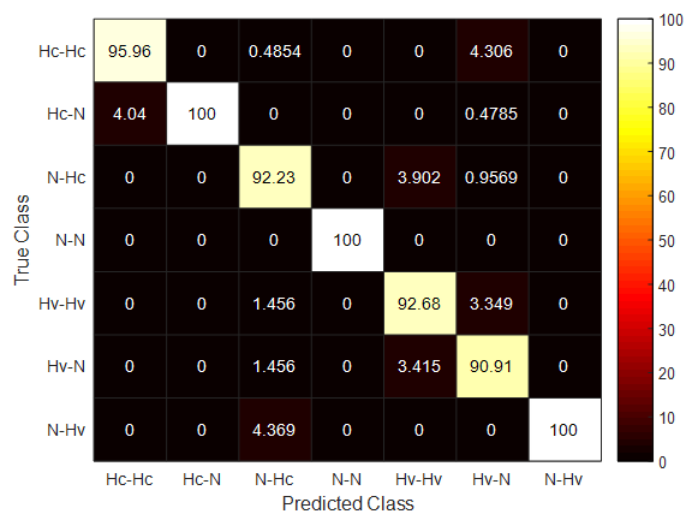

Figure 7. Confusion matrix of KNN using the current feature set

\section{CONCLUSION}

In this research, the impact of current features and voltage features on the identification of multiple harmonic sources has been investigated. Besides, the performances of proposed feature sets are validated using the machine learning algorithm, namely LDA and KNN. The experimental results show that the current 
features are more capable of enhancing the accuracy of harmonic source identification rather than using voltage features. Also, current features were good in the diagnostic process, which showed high discriminative power in this work. The results also prove that the performance of LDA was better than KNN in harmonic sources identification. In the future, the combination of current features and LDA can be applied to other power quality applications.

\section{ACKNOWLEDGMENTS}

This research is supported by the Advanced Digital Signal Processing Laboratory (ADSP Lab). Special thanks also to the Faculty of Electrical \& Electronic Engineering Technology of Universiti Teknikal Malaysia Melaka (UTeM), Center for Robotics and Industrial Automation (CeRIA) of UTeM and Ministry of Higher Education Malaysia (MOHE). Their support is gratefully acknowledged.

\section{REFERENCES}

[1] A. Dixit and M. Kaur, "Harmonic source identification with optimal placement of PMUs," 2016 IEEE 1st International Conference on Power Electronics, Intelligent Control and Energy Systems (ICPEICES), Delhi, pp. 1-6, 2016.

[2] N. H. H. Abidullah, A. R., Zuri_Sha'ameri, A., Shamsudin, and N. H., Ahmad, "Real-Time Power Quality Disturbances Detection and Classification System,” World Applied Sciences Journal, vol. 32, no. 8, pp. 1637-1651, 2014

[3] Victor, L. R. L., Karim, K. A., and Sundram, R., "Improved torque control performance of direct torque control for 5-phase induction machine," International Journal of Power Electronics and Drive Systems, vol. 3, no. 4, pp. 391399, Dec 2019.

[4] F. Safargholi, K. Malekian and W. Schufft, "On the Dominant Harmonic Source Identification - Part I: Review of Methods," in IEEE Transactions on Power Delivery, vol. 33, no. 3, pp. 1268-1277, June 2018.

[5] L. R. L. V. Raj, A. Jidin, C. W. M. F. Che Wan Mohd Zalani, K. Abdul Karim, W. Y. Goh and M. H. Jopri, "Improved performance of DTC of five-phase induction machines," 2013 IEEE 7th International Power Engineering and Optimization Conference (PEOCO), Langkawi, pp. 613-618, 2013.

[6] I. M. Saadon, J. H. Hassanudin, N. Norddin, and W. H. W. Hassan, "Off-grid photovoltaic automated river debris collector system," Proceedings of Mechanical Engineering Research Day 2017, vol. 2017, pp. 168-169, 2017.

[7] N. A. Abidullah, and N. H. Shamsudin, "Performance Verification of Power Quality Signals Classification System," Applied Mechanics and Materials, vol. 752-753, pp. 1158-1163, April 2015.

[8] T. Zang, Y. Yang, Z. He and Q. Qian, "A novel software for harmonic analysis and harmonic source location," 2014 IEEE 5th International Conference on Software Engineering and Service Science, Beijing, pp. 116-119, 2014.

[9] W. Tee, M. R. Yusoff, N. S. N. Anwar, and H. Musa, "Spectrogram based window selection for the detection of voltage variation," International Journal of Integrated Engineerin., vol. 11, no. 3, pp. 240-247, 2019.

[10] A. R. Abdullah, N. S. Ahmad, N. Bahari, M. Manap, A. Jidin and M. H. Jopri, "Short-circuit switches fault analysis of voltage source inverter using spectrogram," 2013 International Conference on Electrical Machines and Systems (ICEMS), Busan, pp. 1808-1813, 2013.

[11] H. Zang, X. Qian and X. Yu, "Innovative Location Research of Multiple Harmonic Sources Based on Statistical Data Correlation," 2012 Asia-Pacific Power and Energy Engineering Conference, Shanghai, pp. 1-4, 2012.

[12] A. F. Noor Azam et al., "Current control of BLDC drives for EV application," 2013 IEEE 7th International Power Engineering and Optimization Conference (PEOCO), Langkawi, pp. 411-416, 2013.

[13] N. A. Abidullah, and G. Z. Peng, "A new two points method for identify dominant harmonic disturbance using frequency and phase spectrogram," International Review of Electrical Engineering, vol. 9, no. 2, pp. 453-459, 2014.

[14] M. H. Jopri, A. R. Abdullah, M. Manap, M. R. Yusoff, T. Sutikno, and M. F. Habban, "An improved detection and classification technique of harmonic signals in power distribution by utilizing spectrogram," International Journal of Electrical and Computer Engineering, vol. 7, no. 1, pp. 12-20, Feb 2017.

[15] N. A. Abidullah, A. R. Abdullah, N. H. Shamsudin, N. H. T. H. Ahmad and M. H. Jopri, "Real-time power quality signals monitoring system," 2013 IEEE Student Conference on Research and Developement, Putrajaya, pp. 433-438, 2013.

[16] M. Jopri, A. Abdullah, T. Sutikno, and M. Manap, "A Utilisation of Improved Gabor Transform for Harmonic Signals Detection and Classification Analysis," International Journal of Electrical and Computer Engineering, vol. 7, no. 1, pp. 21-28, 2017.

[17] N. a. Abidullah, N. H. Shamsudin, and N. H. H. Ahmad, "Power Quality Signals Classification System Using Time-Frequency Distribution," Applied Mechanics and Materials, vol. 494-495, pp. 1889-1894, Feb 2014.

[18] Il-Yop Chung et al., "Development of power quality diagnosis system for power quality improvement," 2003 IEEE Power Engineering Society General Meeting (IEEE Cat. No.03CH37491), Toronto, Ont, vol. 2, pp. 1256-1261, 2003.

[19] M. H. Jopri, A. R. Abdullah, T. Sutikno, M. Manap, M. R. Ab. Ghani, and M. R. Yusoff, "A critical review of time-frequency distribution analysis for detection and classification of harmonic signal in power distribution system," International Journal of Electrical and Computer Engineering, vol. 8, no. 6, pp. 4603-4618, Dec 2018.

[20] A. R. Abdullah, N. Abidullah, and M. H. Jopri, "Analysis of Power Quality Disturbances Using Spectrogram and S-transform," International Review of Electrical Engineering, vol. 9, no. 3. pp. 611-619, 2014.

[21] M. Z. R. Zuber Ahmadi, A. Jidin, K. b. Jaffar, M. N. Othman, R. N. P. Nagarajan and M. H. Jopri, "Minimization 
of torque ripple utilizing by 3-L CHMI in DTC," 2013 IEEE 7th International Power Engineering and Optimization Conference (PEOCO), Langkawi, pp. 636-640, 2013.

[22] N. Z. Saharuddin, N. A. Abidullah, and N. S. Ahmad, "Performance Comparison of VSI Switches Faults Analysis Using STFT and S Transform," Applied Mechanics and Materials, vol. 785, pp. 210-214, August 2015.

[23] A. R. Abdullah, N. Norddin, N. Q. Zainal Abidin, A. Aman and M. H. Jopri, "Leakage current analysis on polymeric and non-polymeric insulating materials using time-frequency distribution," 2012 IEEE International Conference on Power and Energy (PECon), Kota Kinabalu, pp. 979-984, 2012.

[24] Skamyin, A., \& Vasilkov, O, "Static load characteristics in the presence of high harmonics," In E3S Web of Conferences, EDP Sciences, vol. 140, p. 10005, 2019.

[25] N. H. T. H. Ahmad, N. A. Abidullah, and N. H. Shamsudin, "Performance Evaluation of Real Power Quality Disturbances Analysis Using S-Transform," Applied Mechanics and Materials, vol. 752-753, pp. 1343-1348, April 2015.

[26] M. H. Jopri, A. R. Abdullah, T. Sutikno, M. Manap, M. R. A. Ghani, and A. S. Hussin, "A diagnostic analytics of harmonic source signature recognition by using periodogram," International Journal of Electrical and Computer Engineering, vol. 8, no. 6, pp. 5399-5408, Dec 2018.

[27] A. Stetco et al., "Machine learning methods for wind turbine condition monitoring: A review," Renewable Energy, vol. 133, pp. 620-635, 2019.

[28] H. M. S. Firdaus, M. Y. Halyani, E. Z. Ahmad, I. Norain, Z. M. Zulfattah, and M. S. Azizi, "Modeling and simulation of doubly fed induction generator for wind turbine," ARPN Journal of Engineering and Applied Sciences, vol. 11, no. 11, pp. 7331-7335, 2016

[29] N. H. Miswan, R. M. Said, N. H. Hussin, K. Hamzah, and E. Z. Ahmad, "Comparative performance of ARIMA and DES models in forecasting electricity load demand in Malaysia," International Journal Electrical Computer Science IJECS-IJENS, vol. 16, no. 1, pp. 6-9, 2015.

[30] I. M. Saadon, H. Windiarti, M. N. Othman, E. Z. Ahmad, and K. A. M. Annuar, "River Debris Management System using Off-Grid Photovoltaic Module," in MATEC Web of Conferences, vol. 97, p. 1070, 2017.

[31] N. K. Ab Majid and F. S. Ismail, "Electronics system thermal management optimization using finite element and Nelder-Mead method," Telecommunication, Computer, Electronics and Control TELKOMNIKA, vol. 17, no. 5, pp. 2268-2275, Oct 2019.

[32] R. Kumar, B. Singh, and D. T. Shahani, "Recognition of Single-stage and Multiple Power Quality Events Using Hilbert-Huang Transform and Probabilistic Neural Network," Journal Elecric Power Components and System, vol. 43, no. 6, pp. 607-619, Apr 2015.

[33] K. A. M. Annuar, I. Irianto, M. H. Harun, M. Halim, I. M. Saadon, and N. A. Rahman, "Particle Swarm Optimization (PSO) for Simulating Robot Movement on Two-Dimensional Space Based on Odor Sensing," Journal of Telecommunication, Electronic and Computer Engineering, vol. 9, no. 2-6, pp. 79-83, 2017.

[34] P. Thakur and A. K. Singh, "Signal processing and AI based diagnosis of power quality disturbances: A review," 2015 International Conference on Energy Economics and Environment (ICEEE), Noida, pp. 1-6, 2015.

[35] A. Moeed Amjad and Z. Salam, "A review of soft computing methods for harmonics elimination PWM for inverters in renewable energy conversion systems," Renewable and Sustainable Energy Reviews, vol. 33, pp. 141-153, 2014.

[36] M. S. S. M. Basir, R. C. Ismail and M. N. M. Isa, "A Novel Double Co-Transformation for a Simple and Memory Efficient Logarithmic Number System," 2020 IEEE International Conference on Semiconductor Electronics (ICSE), Kuala Lumpur, Malaysia, pp. 25-28, 2020

[37] N. Q. Z. Abidin, N. Norddin, and A. Aman, "Online Surface Condition Monitoring System using Time Frequency Distribution on High Voltage Insulator," Australian Journal of Basic and Applied Sciences, vol. 7, no. 11, pp. 7-14, Sep 2013.

[38] H. R. Baghaee, D. Mlakić, S. Nikolovski and T. Dragicčvić, “Anti-Islanding Protection of PV-Based Microgrids Consisting of PHEVs Using SVMs," in IEEE Transactions on Smart Grid, vol. 11, no. 1, pp. 483-500, Jan. 2020.

[39] M. F. B. Habban, M. Manap, A. R. Abdullah, M. H. Jopri, and T. Sutikno, "An evaluation of linear time frequency distribution analysis for VSI switch faults identification," International Journal of Power Electronics and Drive System, vol. 8, no. 1, pp. 1-9, 2017.

[40] Z. Yin, Y. Sun and T. Yu, "New methods exploration for harmonic source identification technologies," 2011 4th International Conference on Electric Utility Deregulation and Restructuring and Power Technologies (DRPT), Weihai, Shandong, pp. 399-402, 2011.

[41] W. Lin, C. Wu, C. Lin and F. Cheng, "Detection and Classification of Multiple Power-Quality Disturbances With Wavelet Multiclass SVM," in IEEE Transactions on Power Delivery, vol. 23, no. 4, pp. 2575-2582, Oct 2008.

[42] A. Mosavi, M. Salimi, S. F. Ardabili, T. Rabczuk, S. Shamshirband, and A. R. Varkonyi-Koczy, "State of the art of machine learning models in energy systems, a systematic review," Energies, vol. 12, no. 7, pp. 1-42, 2019.

[43] K. E. Y. Ronald E. Walpole, Raymond H. Myers, Sharon L. Myers, "Probability and Statistics for Engineers and Scientists," 9th Edition, 9th ed. Pearson Education, 2012.

[44] M. H. Jopri, A. R. Abdullah, M. Manap, M. F. Habban, and T. Sutikno, "An accurate classification method of harmonic signals in power distribution system by utilising S-transform," Telecommunication, Computer, Electronics and Control TELKOMNIKA, vol. 15, no. 1, pp. 1-8, 2017.

[45] M. F. Omar, R. Ghazali, I. M. Saadon, M. K. Aripin, Y. M. Sam, and C. C. Soon, "Optimal Control for Sport Utility Vehicle System Using Linear Quadratic Integral Control Approach,” Journal of Telecommunication, Electronic and Computer Engineering, vol. 10, no. 4, pp. 143-149, 2018.

[46] W. Feng, J. Sun, L. Zhang, C. Cao and Q. Yang, "A support vector machine based naive Bayes algorithm for spam 
filtering," 2016 IEEE 35th International Performance Computing and Communications Conference (IPCCC), Las Vegas, NV, pp. 1-8, 2016.

[47] J. Too, A. R. Abdullah, and N. M. Saad, "A new co-evolution binary particle swarm optimization with multiple inertia weight strategy for feature selection," Informatics, vol. 6, no. 2, pp. 1-14, 2019.

[48] R. A. S. Fernandes, S. M. Ranzini, I. N. Silva and M. Oleskovicz, "Wrapper attribute selector and intelligent systems applied to the identification of residential harmonic sources," 2012 IEEE Power and Energy Society General Meeting, San Diego, CA, pp. 1-7, 2012.

[49] AL-Hamad, Mohamed Y., and Isa S. Qamber. "GCC electrical long-term peak load forecasting modeling using ANFIS and MLR methods," Arab Journal of Basic and Applied Sciences, vol. 26, no. 1, pp. 269-282, 2019.

[50] R. Nair, A. Jidin, M. N. Othman, M. H. Jopri and M. Manap, "Comparison performance of 3-Level and 5-Level Cascaded H-Bridge multilevel inverter of DTC of Induction Machine," 2013 International Conference on Electrical Machines and Systems (ICEMS), Busan, pp. 2100-2104, 2013.

[51] S. Zhang, D. Cheng, Z. Deng, M. Zong, and X. Deng, "A novel kNN algorithm with data-driven k parameter computation," Pattern Recognition Letters, vol. 109, pp. 44-54, July 2018.

[52] F. Ucar, O. F. Alcin, B. Dandil, and F. Ata, "Power quality event detection using a fast extreme learning machine," Energies, vol. 11, no. 1, pp. 1-14, 2018

[53] J. Too and A. Rahim Abdullah, "Binary atom search optimisation approaches for feature selection," Journal Connection Science, 2019.

[54] L. R. L. V. Raj, A. Jidin, Z. Ibrahim, K. A. Karim, M. A. Said and M. H. Jopri, "Optimal torque control performance of DTC of 5-phase induction machine," 2013 International Conference on Electrical Machines and Systems (ICEMS), Busan, pp. 2094-2099, 2013.

[55] Dragan Mlakić, Srete Nikolovski, and Ljubomir Majdandžić, "Deep Learning Method and Infrared Imaging as a Tool for Transformer Faults Detection,” Journal of Electrical Engineering, vol. 6, no. 2, pp. 98-106, 2018.

[56] A. E. Lazzaretti, D. M. J. Tax, H. Vieira Neto, and V. H. Ferreira, "Novelty detection and multi-class classification in power distribution voltage waveforms," Expert Systems with Applications, vol. 45, no. 1, pp. 322-330, 2016.

[57] D. Mlakić, S. Nikolovski and Z. Baus, "Detection of faults in electrical panels using deep learning method," 2017 International Conference on Smart Systems and Technologies (SST), Osijek, pp. 55-61, 2017.

[58] J. Too, A. R. Abdullah, and N. Mohd Saad, "Binary Competitive Swarm Optimizer Approaches for Feature Selection," Computation, vol. 7, no. 2, pp. 1-17, June 2019.

[59] D. Won and S. Moon, "Optimal Number and Locations of Power Quality Monitors Considering System Topology," in IEEE Transactions on Power Delivery, vol. 23, no. 1, pp. 288-295, Jan 2008.

[60] H. R. Baghaee, D. Mlakić, S. Nikolovski and T. Dragicčvić, "Anti-Islanding Protection of PV-Based Microgrids Consisting of PHEVs Using SVMs," in IEEE Transactions on Smart Grid, vol. 11, no. 1, pp. 483-500, Jan 2020.

[61] H. R. Baghaee, D. Mlakić, S. Nikolovski and T. Dragicević, "Support Vector Machine-Based Islanding and Grid Fault Detection in Active Distribution Networks," in IEEE Journal of Emerging and Selected Topics in Power Electronics, vol. 8, no. 3, pp. 2385-2403, Sept. 2020.

[62] N. H. T. Huda, A. R. Abdullah and M. H. Jopri, "Power quality signals detection using S-transform," 2013 IEEE 7th International Power Engineering and Optimization Conference (PEOCO), Langkawi, pp. 552-557, 2013.

[63] Shklyarskiy, Yaroslav, Aleksandr Skamyin, Iaroslav Vladimirov, and Farit Gazizov, "Distortion Load Identification Based on the Application of Compensating Devices," Energies, vol. 13, no. 6, p. 1430, 2020.

[64] N. M. Kassim, N. A. Ngatiman, and M. R. Yusoff, "Localization of Multiple Harmonic Sources for Inverter Loads Utilizing Periodogram," Journal of Telecommunication, Electronic and Computer Engineering, vol. 8, no. 2, pp. 87-91, 2016.

[65] Langella Roberto, Testa, Alfredo, "IEEE 519 Recommended Practice and Requirements for Harmonic Control in Electric Power Systems," IEEE Recommended Practice, vol. 2014, 2014.

[66] "IEEE Standard Definitions for the Measurement of Electric Power Quantities Under Sinusoidal, Nonsinusoidal, Balanced, or Unbalanced Conditions," in IEEE Std 1459-2010 (Revision of IEEE Std 1459-2000), pp.1-50, 19 March 2010. 